\title{
Dental Extractions in Patients on Antiplatelet Therapy: A Clinical Study
}

\author{
${ }^{1} \mathrm{KN}$ Sushma, ${ }^{2}$ Jayaprasad N Shetty, ${ }^{3}$ Vijayendra Pandey, ${ }^{4}$ Somnath Mukherjee, ${ }^{5}$ Santosh Kumar
}

\begin{abstract}
Cardiovascular diseases cause highest mortality and morbidity worldwide. The introduction of preventive and maintenance antiplatelet therapy has, to a certain extent, contributed to this decline. With millions of health-conscious people using antiplatelet drugs, dental practitioners are frequently confronted with clinical situations wherein a decision has to be made about patient management, in view of the medical history. The aim of this study is to assess the need to stop aspirin before minor oral surgical procedures, including simple and surgical extractions and to discuss the various measures implemented for controlling the bleeding postoperatively. This study analyzes the association of increased bleeding during and after tooth extraction or any other minor oral surgical procedures with patients on antiplatelet therapy. The aim of this study is to assess the need to stop aspirin before minor oral surgical procedures, including simple and surgical extractions, and to discuss the various measures implemented for controlling the bleeding postoperatively. The objectives of the study are to analyze association of increased bleeding during and after tooth extraction or any other minor oral surgical procedures with patients on antiplatelet therapy.
\end{abstract}

Keywords: Acitrom, Antiplatelets, Aspirin, Bleeding, Clopidogrel, Dental extractions, Heparin, Sorbitrate.

How to cite this article: Sushma KN, Shetty JN, Pandey V, Mukherjee S, Kumar S. Dental Extractions in Patients on Antiplatelet Therapy: A Clinical Study. Int J Recent Surg Med Sci 2017;3(1):34-39.

Source of support: Nil

Conflict of interest: None

\section{INTRODUCTION}

Cardiovascular diseases cause highest mortality and morbidity worldwide. With increasing awareness, health consciousness, and preventive and preemptive strategies, there is a striking decrease of cardiovascular mortality, resulting in fewer deaths compared with the earlier

\footnotetext{
${ }^{1}$ Senior Lecturer, ${ }^{2} \mathrm{Head},{ }^{3}$ Professor, ${ }^{4}$ Reader, ${ }^{5}$ Postgraduate Student

${ }^{1,4}$ Department of Oral and Maxillofacial Surgery, Vananchal Dental College \& Hospital, Garhwa, Jharkhand, India

${ }^{2}$ Department of Oral and Maxillofacial Surgery, Oxford Dental College and Hospital, Bengaluru, Karnataka, India

${ }^{3}$ Department of Periodontics, Vananchal Dental College \& Hospital, Garhwa, Jharkhand, India

${ }^{5}$ Department of Orthodontics, Vananchal Dental College \& Hospital, Garhwa, Jharkhand, India

Corresponding Author: KN Sushma, Senior Lecturer, Department of Oral and Maxillofacial Surgery, Vananchal Dental College \& Hospital, Garhwa, Jharkhand, India, Phone: +917091502978 e-mail: sushukn@gmail.com
}

decades. The introduction of preventive and maintenance antiplatelet therapy has to a certain extent contributed to this decline. Antiplatelet therapy has reported to have been reduced the overall mortality of vascular disease by $15 \%$ and nonfatal vascular complications by $30 \% .{ }^{1}$ With millions of health-conscious people using antiplatelet drugs, dental practitioners are frequently confronted with clinical situations wherein a decision has to be made about patient management, in view of the medical history. ${ }^{2,3}$

Till the very recent past, the recommendation was to stop antiplatelet therapy and to avoid excessive postoperative bleeding. The stoppage of antiplatelet therapy was recommended for a variable period, i.e., from 3 to 7 days before the planned event. ${ }^{4-6}$ There was a total lack of awareness or understanding of the thromboembolic events compared with hemorrhagic risks. There has been a reawakening of interest in this hitherto ununderstood risk.

Antiplatelet drugs are used to prevent or treat thromboembolic disorders, which play a key role in cardiovascular diseases. ${ }^{78}$ Given the fact that the antiaggregant mechanism of action consists in inhibiting the platelet function by preventing aggregation, the initial phase of hemostasis, use of these drugs can make patients more susceptible to hemorrhages. This is of vital importance in the daily practice of dentists, particularly when performing surgery, such as dental extractions. In the past, a bleeding time analysis was conducted in order to assess the hemorrhage risk level for these patients. ${ }^{9-11}$ This test was subsequently replaced by more sophisticated ones, such as the PFA-100 or the platelet aggregation measurement by the impedance method. However, there is no analytical test which serves to conclusively evaluate the risk of bleeding in these patients.

Aspirin, clopidogrel, acitrom, heparin, sorbitrate, etc., have been used for secondary prevention of myocardial infarction or stroke in patients with ischemic heart or cerebrovascular disease for decades, and its efficacy has been well documented. Aspirin is therefore, strongly recommended as a lifelong therapy after coronary or cerebrovascular event. In spite of evidence to the benefit of antiplatelet therapy, aspirin treatment is often discontinued before surgery for the fear of perioperative bleeding. 12,13 Thus exists the question of whether to continue or discontinue aspirin in the perioperative period. Hence, the study was conducted with the primary aim to assess the incidence of perioperative bleeding in patients with low-dose aspirin treatment after minor oral surgical procedures. 
Dental Extractions in Patients on Antiplatelet Therapy

\begin{tabular}{lll}
\hline & Table 1: Gender distribution in the study \\
\hline Sl. no. & Gender distribution & No. of patients \\
\hline 1 & Male & 74 \\
2 & Female & 26 \\
\hline Total & & 100 \\
\hline
\end{tabular}

This study was done to evaluate the postoperative bleeding following extractions in patients who are on antiplatelet therapy.

\section{MATERIALS AND METHODS}

This study involved 100 patients in whom extractions were done during the period from June 2013 to June 2014 (Table 1). All of these patients were on antiplatelet therapy for over 1 week to 6 years -mono or dual/combination with different indications (Table 2, Graphs 1 to 7). The gender distribution for patients in whom extraction were indicated for caries and periodontal problems as shown in Graphs 4 and 5. These patients reported to the Department of Oral and Maxillofacial Surgery at the Oxford Dental College and Hospital, Bommanahalli,

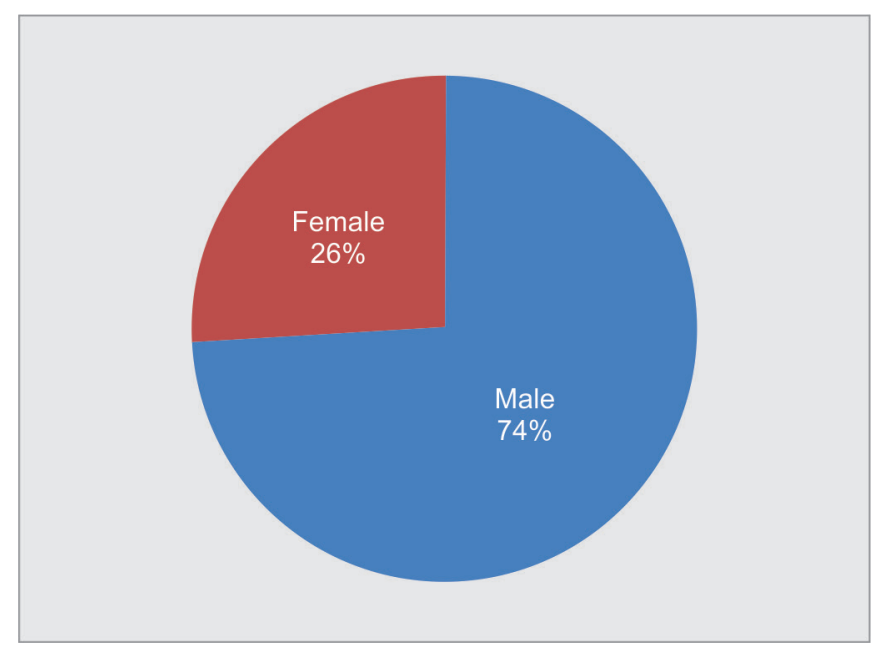

Graph 1: Gender distribution in the study population

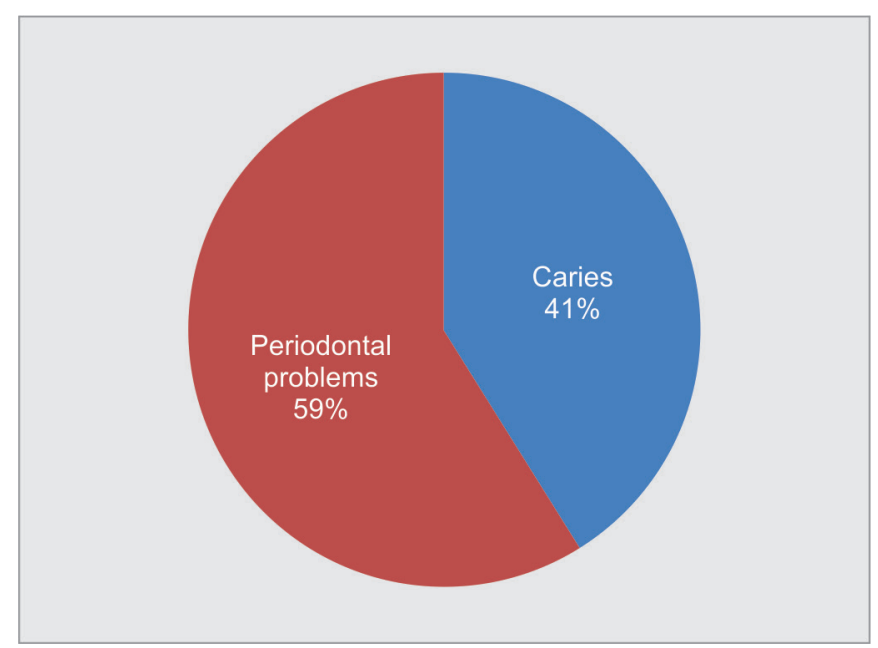

Graph 3: Indications for extractions
Table 2: Distribution of antiplatelet therapy in the study

\begin{tabular}{lll}
\hline Sl. no. & Antiplatelet therapy & No. of patients \\
\hline 1 & Single therapy & 65 \\
2 & Dual/combination therapy & 35 \\
\hline Total & & 100 \\
\hline
\end{tabular}

Bangalore, Karnataka, India. The gender distribution in the study population was depicted in Graph 1 and 3 shows the indications for which extractions were done.

\section{Inclusion Criteria}

- Patients included in the study were in the age group of 30 to 80 years.

- Patients should be on antiplatelet therapy for various indications (Tables 3 to 5 and Graph 6).

\section{Exclusion Criteria}

The patients with congenital or acquired bleeding disorders with a potential for bleeding, a history of gastrointestinal bleeding or intracranial hemorrhage, patients with hematologic, renal, or liver disease; bone marrow

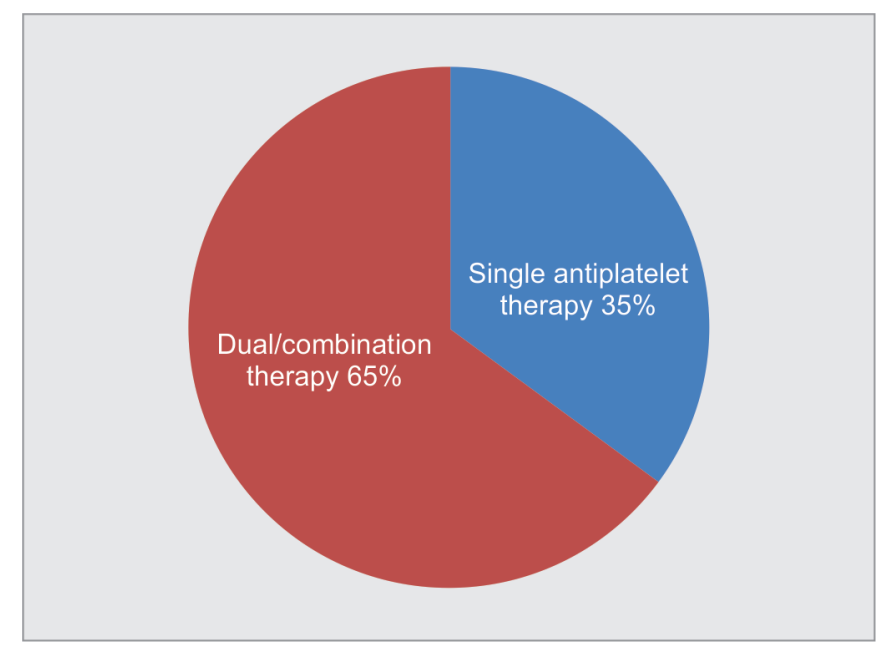

Graph 2: Distribution for antiplatelet therapy

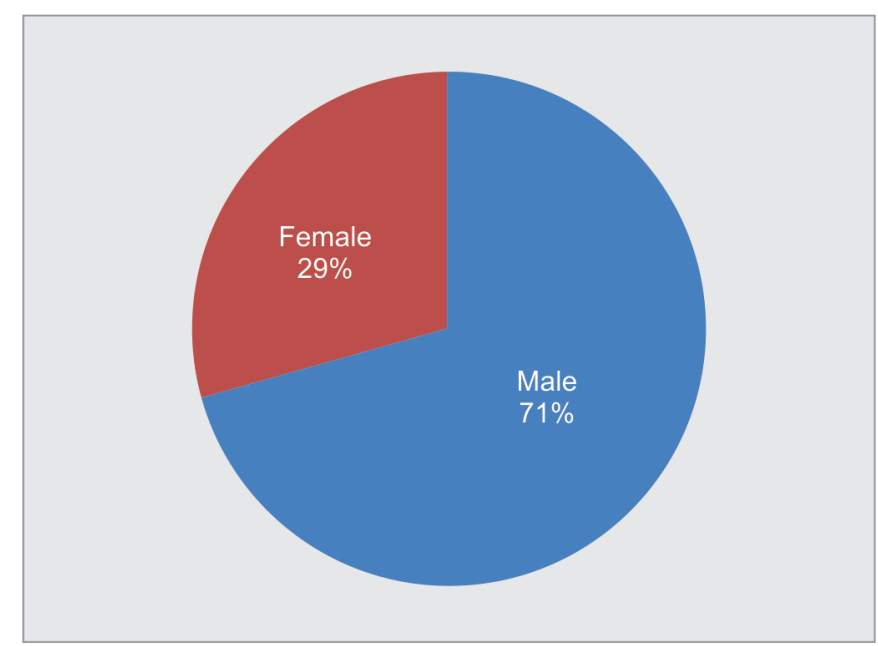

Graph 4: Gender distribution for patients in whom extractions were indicated for caries 


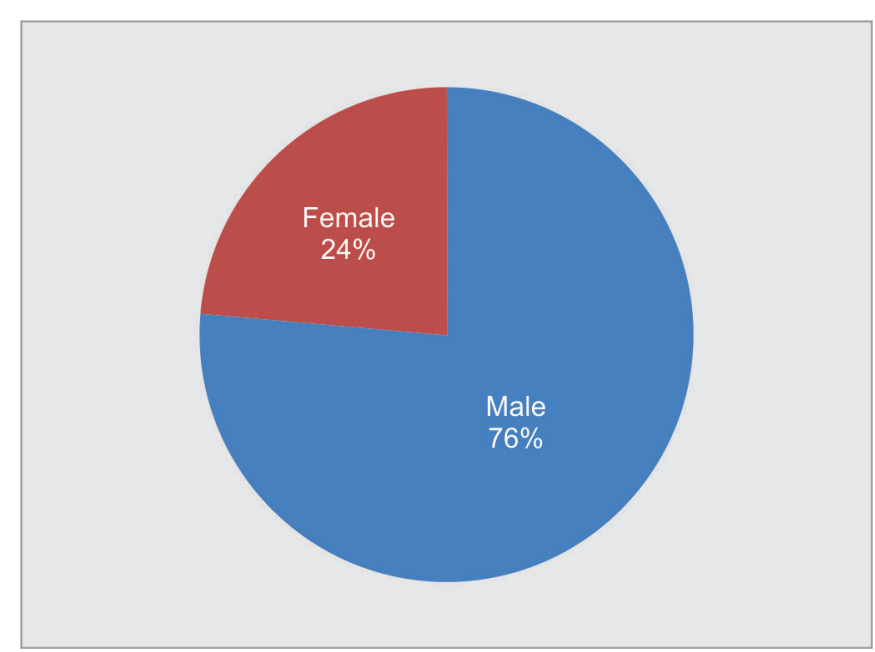

Graph 5: Gender distribution for patients in whom extractions were indicated for periodontal problems

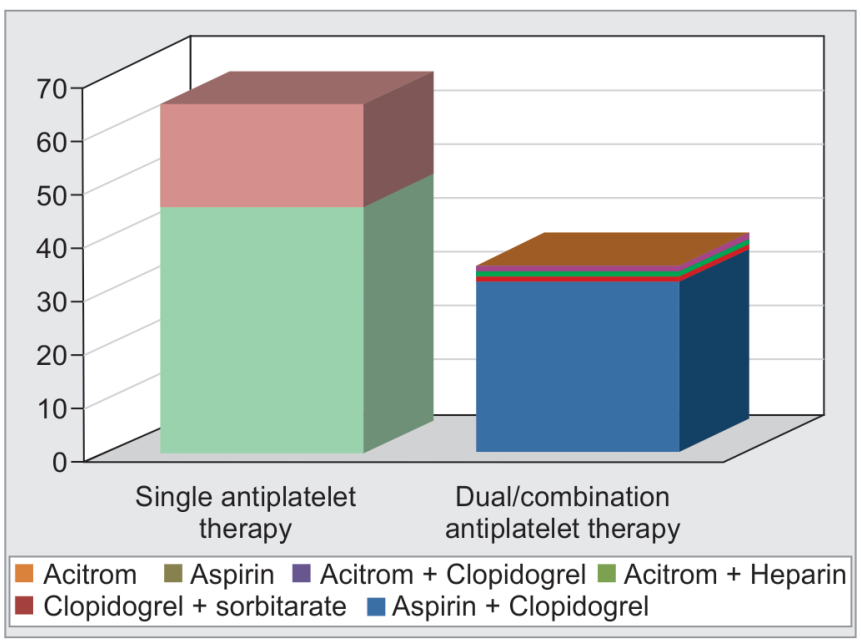

Graph 7: Distribution of antiplatelet therapy

disorders; alcoholism, or any concurrent medications affecting hemostasis were excluded from the study.

\section{Methods}

The patients were informed that they were part of a study investigating if extractions can be done without discontinuing antiplatelet drugs without any hemorrhagic complications, and written informed consent was obtained. The extractions were performed on patients on antiplatelet therapy with the advice not to discontinue the antiplatelet drug prior to extractions. At initial consultation, a past medical history, clinical examination were carried out and recorded. Extractions were carried out under local anesthesia (lignocaine $\mathrm{HCl}$ solution $2 \%$ with epinephrine 1:2,00,000) and sutures were placed. Patients were instructed to bite on a moistened gauze pack for 30 minutes. Patients were kept under observation for a further period of 30 minutes and evaluated for bleeding before leaving. If bleeding persisted after 30 minutes, it was by our definition considered as prolonged immediate

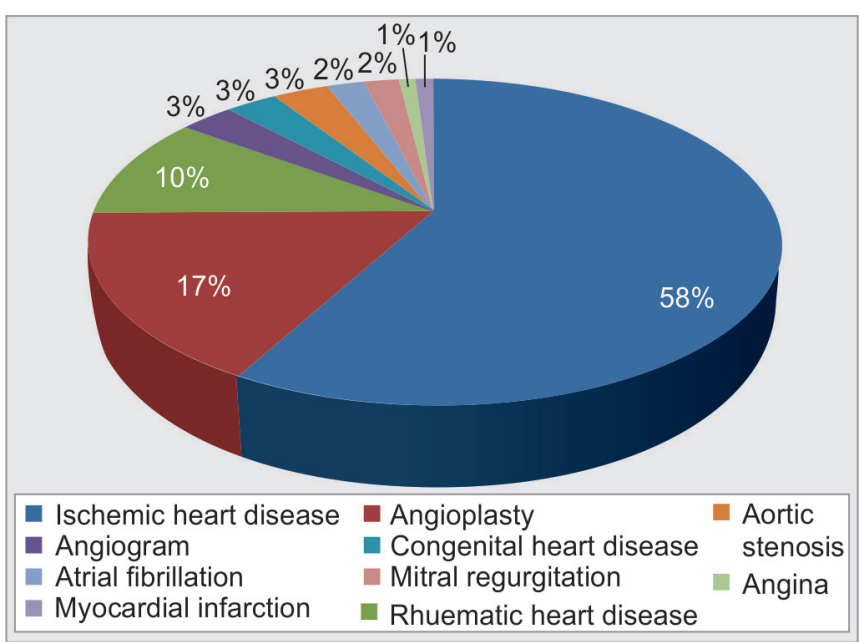

Graph 6: Indications for antiplatelet therapy

Table 3: Indications for extractions of teeth

\begin{tabular}{lll}
\hline Sl. no. & Indications for extractions of teeth & No. of patients \\
\hline 1 & Caries & 59 \\
2 & Periodontal problems & 41 \\
\hline Total & & 100 \\
\hline
\end{tabular}

Table 4: Gender distribution and indications for extractions

\begin{tabular}{lllll}
\hline SI. no. & Indications & $\begin{array}{l}\text { No. of } \\
\text { patients }\end{array}$ & Gender & $\begin{array}{l}\text { No. of } \\
\text { patients }\end{array}$ \\
\hline 1 & Caries & 41 & Male & $29(70.7 \%)$ \\
& & & Female & $12(29.2 \%)$ \\
2 & Periodontal problems & 59 & Male & $45(76.2 \%)$ \\
& & & Female & $14(23.7 \%)$ \\
\hline Total & & & & 100 \\
\hline
\end{tabular}

Table 5: Indications for single, dual/ combination antiplatelet therapy

\begin{tabular}{cll}
\hline Sl. no. & Indications & $\begin{array}{l}\text { No. of } \\
\text { patients }\end{array}$ \\
\hline 1 & Ischemic heart disease & 58 \\
2 & Angioplasty & 17 \\
3 & Rheumatic heart disease & 10 \\
4 & Angiogram & 3 \\
5 & Congestive heart disease & 3 \\
6 & Aortic stenosis & 3 \\
7 & Atrial fibrillation & 2 \\
8 & Mitral regurgitation & 2 \\
9 & Angina & 1 \\
10 & Myocardial infarction & 1 \\
\hline
\end{tabular}

postextraction bleeding. In such cases, resorbable gelatin sponge soaked in hemocoagulase was plugged into the extraction socket and sutures were placed. All patients were given appropriate postoperative instructions and were advised to report immediately in the event of any hemorrhagic complication. Patients' conditions were enquired over the telephone 24 and 48 hours postextraction, and complaints of bleeding, if any were recorded. Sutures were removed after 7 days. 


\section{RESULTS}

In this study, 74 male and 26 female patients in the age range of 30 to 80 years meeting the inclusion criteria were enrolled. These patients were on antiplatelet drugs like acetyl salicylic acid (aspirin), clopidogrel, and acenocoumarol.

Out of these, 35 patients were on dual/combination and the remaining 65 patients were on single antiplatelet therapy. Extractions were indicated in these patients for dental caries (41\%) and periodontal problems (59\%).

Prolonged intraoperative bleeding, i.e., excessive loss of blood, at the time of extraction was seen in four patients (6\%) among single antiplatelet therapy group and in seven patients (20\%) among the group on dual/combination therapy. All prolonged bleeding complications were treated successfully with local hemostatic measures by placing resorbable gelatin $(\mathrm{AbGel})$ in the extraction socket and sutures were placed.

There was no hemorrhagic complication seen in patients who were kept under observation for 30 minutes postoperatively (Table 6, Graph 8). Phone inquiries were made 24 and 48 hours postextraction, and none of the patients complained of any hemorrhagic complications. Each patient was recalled after 1 week postoperatively, checked for any hemorrhagic complication, and sutures were removed.

The prolonged intraoperative bleeding seen in $11 \%$ of these patients is found to be neither clinically nor statistically significant. These findings suggest that there is no indication to discontinue antiplatelet therapy for patients requiring extraction of teeth.

Thus, discontinuation of antiplatelet therapy is considered unnecessary in minor oral surgical procedures that have a low risk of hemorrhage. Antiplatelet medications should only be discontinued when the hemorrhagic risk is absolutely greater than the cardiovascular risk associated with their discontinuation.

\section{DISCUSSION}

Longstanding dogma concerning the exaggerated risk for hemorrhage in patients who are on antiplatelet therapy, during and after minor oral surgical procedures, results in a treatment plan that often leads to discontinuation of the antiplatelet therapy. ${ }^{14-16}$ Because of the paucity of literature on this subject, this study aims to assess the risks that are of concern, specifically excessive intraoperative, immediate postoperative, and late postoperative hemorrhagic complications. The oral and maxillofacial surgeons frequently require treating patients who are receiving antiplatelet therapy for prophylaxis against cardiovascular disease conditions like myocardial infarction, ischemic stroke, peripheral arterial insufficiency, etc. ${ }^{17}$ Although low doses of antiplatelet drugs can prevent cardiovascular disease outcomes, the risk for hemorrhage after dental extraction may be increased. ${ }^{18-19}$

Original recommendations had been discontinuation of acetyl salicylic acid 7 to 10 days prior to surgical procedures. ${ }^{20-23}$ More recently, it was discussed that antiplatelet therapy can be discontinued for 3 days prior to surgical procedures, which would ensure that a sufficient number of new platelets are released into the circulation. Nevertheless, interruption of the antiplatelet therapy may expose these patients to risk of developing thromboembolism, myocardial infarction, or cerebrovascular accident. $^{24,25}$ Therefore, there has been some debate whether, prior to minor oral surgery, antiplatelet therapy should be discontinued or not? The risk of serious postoperative hemorrhage has to be balanced against the potential for life-threatening thromboembolism.

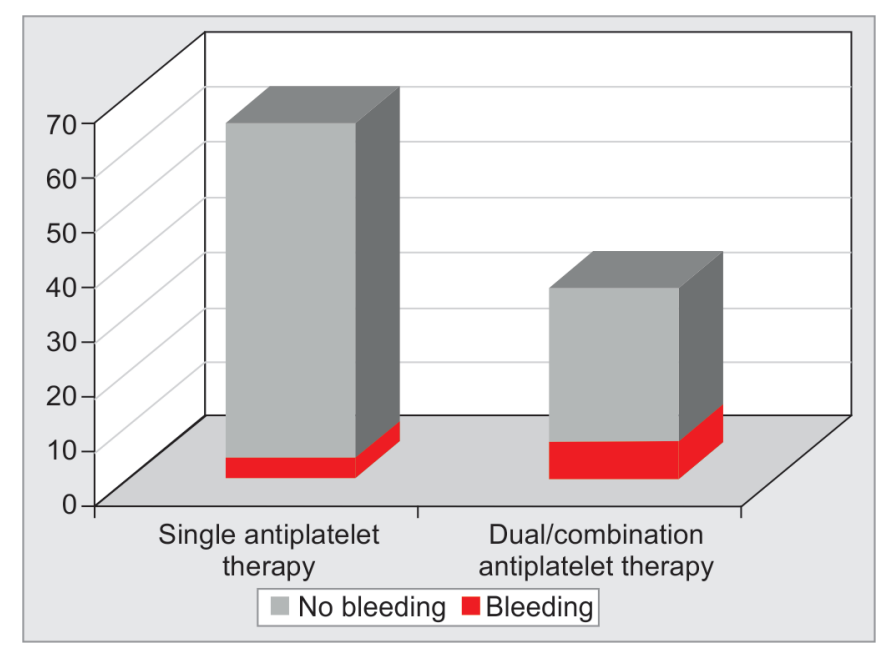

Graph 8: Hemorrhagic complications in patients on single and dual/combination therapy

Table 6: Hemorrhagic complications in patients on single, dual/combination therapy

\begin{tabular}{|c|c|c|c|c|c|}
\hline \multirow[b]{2}{*}{ Antiplatelet therapy } & & \multirow{2}{*}{\multicolumn{2}{|c|}{ No. of patients }} & \multicolumn{2}{|c|}{ No. of patients who had bleeding } \\
\hline & & & & $\begin{array}{l}\text { Immediate } \\
\text { (intraoperative) }\end{array}$ & $\begin{array}{l}\text { Postoperative bleeding } \\
(24 \text { hrs, } 48 \text { hrs, } 1 \text { week) }\end{array}$ \\
\hline \multirow[t]{2}{*}{ Single } & Aspirin (75-325 mg) & 46 & 65 & $4(6.15 \%)$ & 0 \\
\hline & Acitrom (1-3 mg) & 19 & & & \\
\hline \multirow[t]{4}{*}{ Dual/combination } & Aspirin + clopidogrel & 32 & 35 & $7(20 \%)$ & 0 \\
\hline & Clopidogrel + sorbitrate & 1 & & & \\
\hline & Acitrom + heparin & 1 & & & \\
\hline & Acitrom + clopidogrel & 1 & & & \\
\hline
\end{tabular}


Recently, several authors suggested that levels of antiplatelet drugs are to be maintained and that any subsequent postextraction hemorrhage is to be treated with local hemostatic measures. Literature showed that most of the authors were in favor of stopping antiplatelet therapy ${ }^{26,27}$ However, several authors reported that most of the minor oral surgical procedures can be carried out safely without stopping long-term low-dose antiplatelet regimen. ${ }^{28}$ Thus patients need not discontinue antiplatelet drugs before extractions, as the hemorrhagic risk is not greater than the thromboembolic risk associated with interruption of the drug regimen. ${ }^{29,30}$ Minor surgical procedures, such as simple extraction of teeth, gingival surgery, crown and bridge procedures, dental scaling, and the surgical removal teeth can be safely carried out without altering the antiplatelet medication dose. ${ }^{31}$

Primary hemostasis was easily achieved with local hemostatic measures in case of intraoperative and/or postoperative hemorrhage. There was no statistically significant intra- and postoperative hemorrhage in any of the patients included in this study. No patient on single/dual/ combination antiplatelet therapy developed clinically significant late hemorrhage. Cardona-Tortajada et al ${ }^{12,32}$ reported late-onset (after 24 hours) postextraction hemorrhage in $17 \%$ of their 155 patients treated with antiplatelet therapy. These complications, however, were mostly mild and self-controlled. The higher frequency of late hemorrhagic events in the study may be associated with short duration of postextraction monitoring, whereas patients in the present study were monitored for 30 minutes and then treated appropriately, wherever necessary. However, the results of our study show no case of late onset postextraction hemorrhage.

Persistent postextraction evaluation may, therefore, facilitate adequate hemostatic control in patients who are on antiplatelet therapy. Morimoto et $\mathrm{al}^{9}$ found that occurrences of postextraction hemorrhage in those patients who were on antiplatelet therapy alone were significantly lower than those patients on antiplatelet and warfarin combination therapy and also in warfarin therapy alone. ${ }^{7,31}$ Patients receiving aspirin and clopidogrel were clearly at a higher risk of immediate postextraction hemorrhage. ${ }^{34}$ However, in their study all cases of hemorrhagic complication were successfully controlled by local hemostatic measures like application of resorbable gelatin into the socket.

Napeñas et $\mathrm{al}^{3,10}$ reported no episodes of prolonged postextraction hemorrhage in 29 patients receiving dual antiplatelet therapy. However, this study was limited by retrospective design, absence of direct assessment of perioperative hemorrhage, and absence of a control arm of patients who were not receiving antiplatelet therapy. As per the results of the present study, although postextraction hemorrhagic events are likely to occur in patients who are on antiplatelet therapy, such events are limited in the immediate postextraction timeframe and are controllable with appropriate local hemostatic measures. ${ }^{35}$

\section{CONCLUSION}

In the present study, 100 patients who were on antiplatelet therapy in the age range of 30 to 80 years were included. Minor oral surgical procedures like extraction of teeth were done in these patients under local anesthesia lignocaine $2 \%$ with 1:200,000 adrenaline. Sutures were placed after extraction of teeth in every patient. The patients were evaluated for 30 minutes postoperative hemorrhage, before discharging the patient. Prolonged intraoperative hemorrhage was seen in $6 \%$ among single antiplatelet therapy group and in $20 \%$ among patients who were on dual/combination therapy. Patient status was followed up 24 hours, 48 hours, and 1 week postoperatively. Patients were followed up after 1 week and sutures were removed. In conclusion, there is no need to discontinue the antiplatelet therapy for patients who have to undergo extraction of teeth since there was no clinically and statistically significant postoperative hemorrhagic complications.

\section{REFERENCES}

1. Little, JW.; Falace, D.; Miller, C.; Rhodus, NL. Dental management of the medically compromised patient. 8th ed. St. Louis: Mosby; 2013.

2. Madan GA, Madan SG, Madan G, Madan AD. Minor oral surgery without stopping daily low dose aspirin therapy: a study of 51 patients. J Oral Maxillofac Surg 2005 Sep;63(9): 1262-1265.

3. Napeñas JJ, Oost FC, DeGroot A, Loven B, Hong $\mathrm{CH}$, Brennan MT, Lockhart PB, van Diermen DE. Review of postoperative bleeding risk in dental patients on antiplatelet therapy. Oral Surg Oral Med Oral Pathol Oral Radiol 2013 Apr;115(4):491-499.

4. Girotra C, Padhye M, Mandlik G, Dabir A, Gite M, Dhonnar R, Pandhi V, Vandekar M. Assessment of the risk of hemorrhage and its control following minor oral surgical procedures in patients on anti-platelet therapy: a prospective study. Int J Oral Maxillofac Surg 2014 Jan;43(1):99-106.

5. Lochkhart PB, Gibson J, Pond SH, Leitch L. Dental management considerations for the patient with an acquired coagulopathy. Part 2: coagulopathies from drugs. Br Dent J 2003 Nov;195(9):495-501.

6. Duygu G, Ozcakir-Tomruk C, Guler N, Sencift K. Assessment of effects of antiplatelet drugs on bleeding risk after teeth extractions. Biotechnol Biotechnol Eq 2010;24(3):2040-2043.

7. Henry RG. Dental management of patients taking antiplatelet medications: Tex Dent J 2009 Jul;126(7):608-616.

8. Cardona-Tortajada F, Sainz-Gómez E, Figuerido-Garmendia J, de Robles-Adsuar AL, Morte-Casabó A, Giner-Muñoz F, Artázcoz-Osés J, Vidán-Lizari J. Dental extractions in patients 
on antiplatelet therapy. A study conducted by the Oral Health Department of the Navarre Health Service (Spain). Med Oral Patol Oral Cir Bucal 2009 Nov;14(11):e588-e592.

9. Morimoto Y, Niwa H, Minematsu K. Risk factors affecting postoperative hemorrhage after tooth extraction in patients receiving oral antithrombotic therapy. J Oral Maxillofac Surg 2011 Jun;69(6):1550-1556.

10. Napeñas JJ, Hong CH, Brennan MT, Furney SL, Fox PC, Lochkart PB. The frequency of bleeding complications after invasive dental treatment in patients receiving single and dual antiplatelet therapy. J Am Dent Assoc 2009 Jun;140(6): 690-695.

11. Garnier J, Truchot F, Quero J, et al. Antiplatelet and oral surgery: about 218 dental extractions. J Oral Maxillofac Surg

12. Potoski M, Amenábar JM. Dental management of patients receiving anticoagulation or antiplatelet treatment. J Oral Sci 2007 Dec;49(4):253-258.

13. Aframian DJ, Lalla RV, Peterson DE. Management of dental patients taking common hemostasis-altering medications. Oral Surg Oral Med Oral Pathol Oral Radiol Endod 2007 Mar;103(Suppl 1):S45.e1-S45.e11.

14. Chassot PG, Delabays A, Spaohn DR. Perioperative antiplatelet therapy: the case for continuing therapy in patients at risk of myocardial infarction. Br J Anaesth 2007 Sep;99(3): 316-328.

15. Brennan MT, Valerin MA, Noll JL, Napeñas JJ, Kent ML, Fox PC, Sasser HC, Lockhart PB. Aspirin use and postoperative bleeding from dental extractions. J Dent Res 2008 Aug;87(8):740-744.

16. North West Medicines Information Center. Surgical management of the primary care dental patient on antiplatelet medication. Liverpool: North West Medicines Information Center; 2007.

17. Morimoto $Y$, Niwa H, Minematsu K. Hemostatic management of tooth extractions in patients on oral antithrombotic therapy. J Oral Maxillofac Surg 2008 Jan;66(1):51-57.

18. Pharmacist's letter. Managing warfarin and anti platelet drugs peri operatively. 2008 Aug;24(240804).

19. Veitch AM, Baglin TP, Gershlick AH, Harnden SM, Tighe R, Cairns S, British Society of Gastroenterology; British Committee for Standards in Haematology; British Cardiovascular Intervention Society. Guidelines for the management of anticoagulant and antiplatelet therapy in patients undergoing endoscopic procedures. Gut 2008 Sep;57(9):1322-1329.

20. Brennan MT, Wynn RL, Miller CS. Aspirin and bleeding in dentistry: an update and recommendations. Oral Surg Oral Med Oral Pathol Oral Radiol Endod 2007 Sep;104(3): 316-323.
21. Bertrand ME. When and how to discontinue antiplatelet therapy. Eur Heart J (Suppl) 2008 Jan;10(Suppl A):A35-A41.

22. Nooh $\mathrm{N}$. The effect of aspirin on bleeding after extraction of teeth. Saudi Dent J 2009 Jul;21(2):57-61.

23. Murphy J, Twohig E, McWilliams SR. Dentists' approach to patients on anti-platelet agents and warfarin: a survey of practice. J Ir Dent Assoc 2009 Dec;56(1):28-31.

24. Jaya Kumar A, Meena Kumari M, Arora N, Haritha A. Is anti platelet therapy interruption a real clinical issue? Its implications in dentistry and particularly in periodontics. J Indian Soc Periodontol 2009 Sep-Dec;13(3):121-125.

25. Oscarsson A, Gupta A, Fredrikson M, Järhult J, Nyström M, Pettersson E, Darvish B, Krook H, Swahn E, Eintrei C. To continue or discontinue aspirin in the perioperative period: a randomized, controlled clinical trial. Br J Anaesth 2010 Mar;104(3):305-312.

26. Lillis T, Ziakas A, Koskinas K, Tsirlis A, Giannoglou G. Safety of dental extractions during uninterrupted single or dual antiplatelet therapy. Am J Cardiol 2011 Oct;108(7):964-967.

27. Raymond Li. Management of anticoagulant and antiplatelet therapy for patients undergoing dental procedures. BC DPIC 2011;19(7):22-23.

28. Yadav S, Sachdeva A, Verma A. Risk of post-extraction bleeding in patients on aspirin therapy. Is it an enigma! J Indian Dent Assoc 2011 Feb;5(2):311-313.

29. Sidana S, Galinde J. Contemporary management of patients on warfarin, aspirin and clopidogrel requiring dentoalveolar surgery. J Contemp Dent 2011 Jun-Sep;1(1):22-25.

30. Kumar A, Khan A, Hingorjo MR, Mehdi A. Tooth extraction and low dose aspirin: common practice in Karachi. J Pak Dent Assoc 2011 Apr-Jun;20(2):115-117.

31. Claramunt Lozano A, Sarrión Perez MG, Gavaldá Esteve C. Dental management in patients with hemostasis alteration. J Clin Exp Dent 2011 Jan;3(2):e120-e126.

32. Badal S, Ahmed S, Shrikanthan R, Badal A. Continuing antiplatelet therapy throughout dental procedures: a clinical dilemma: J Interdiscip Dent 2012 Jan-Apr;2(1):15-19.

33. Al-Harkan AM, Al Ayoub GA. Should antiplatelet and anticoagulant medications be discontinued before minor oral surgery procedures? J Can Dent Assoc 2012;78:c24.

34. Bajkin BV, Bajkin IA, Petrovic BB. The effects of combined oral anticoagulant-aspirin therapy in patients undergoing tooth extractions - a prospective study. J Am Dent Assoc 2012 Jul;143(7):771-776.

35. Park MW, Her SH, Kwon JB, Lee JB, Choi MS, Cho JS, Kim DB, Chung WS, Seung KB, Kim KY. Safety of dental extractions in coronary drug eluting stenting patients without stopping multiple antiplatelet agents. Clin Cardiol 2012 Apr;35(4):225-230. 